\title{
Effect of TW37 on the growth of H1975 EGFR-TKI-resistant lung cancer cells and its underlying mechanisms
}

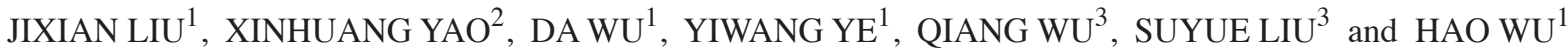 \\ ${ }^{1}$ Department of Thoracic Surgery, Peking University Shenzhen Hospital; \\ ${ }^{2}$ Central Laboratory of Peking University Shenzhen Hospital; ${ }^{3}$ Department of Thoracic Surgery, \\ Anhui Medical University Shenzhen Clinical College, Shenzhen, Guangdong 518036, P.R. China
}

Received May 27, 2016; Accepted April 5, 2017

DOI: $10.3892 / \mathrm{mmr} .2017 .8181$

\begin{abstract}
Previous studies have suggested that the B-cell lymphoma 2 (Bcl-2) inhibitor, TW37, may induce apoptosis of the non-small cell lung cancer cell line, H1975/epidermal growth factor receptor-tyrosine kinase inhibitor (EGFR-TKI), which exhibits secondary resistance to EGFR-TKI. However, the effects of TW37 on H1975/EGFR-TKI cells remain unclear. The aim of the present study was to investigate the effects of TW37 on the growth of H1975/EGFR-TKI cells and explore the underlying mechanisms. An in vitro study was performed, whereby H1975/EGFR-TKI cells were treated with serially increasing concentrations of TW37. MTT, flow cytometry, migration and transwell invasion assays were preformed to investigate the proliferation, apoptosis, migration and invasion of H1975/EGFR-TKI cells, respectively. In addition, reverse transcription-polymerase chain reaction and western blot analyses were performed to detect the mRNA and protein expression levels of apoptosis-associated factors, respectively. An enzyme-linked immunosorbent assay was performed to detect phosphatidylinositol $[3,4,5]$ tris-phosphate (PIP3) expression. The results suggested that the mRNA and protein expression levels of Bcl-2 were significantly decreased in TW37-treated cells when compared with the untreated control group. Following treatment with TW37, the proliferation, migration and invasion ability of H1975/EGFR-TKI cells decreased in a dose-dependent manner, while the percentage of apoptotic cells increased. In addition, the results demonstrated that TW37 reduced the expression of PIP3 and the phosphorylation of AKT serine/threonine kinase 1 (AKT) in H1975/EGFR-TKI cells in a dose-dependent manner. In conclusion, TW37 inhibited H1975/EGFR-TKI cell growth
\end{abstract}

Correspondence to: $\mathrm{Dr} \mathrm{Hao} \mathrm{Wu}$, Department of Thoracic Surgery, Peking University Shenzhen Hospital, 1120 Lianhua Road, Shenzhen, Guangdong 518036, P.R. China

E-mail:wuhao05271@163.com

Key words: TW37, B-cell lymphoma 2, non-small cell lung cancer, cell growth and induced cell apoptosis potentially via suppression of AKT signaling pathway activation.

\section{Introduction}

With high incidence and mortality rates, lung cancer is one of the most common malignancies worldwide. The incidence of lung cancer in China currently increasing, and presents a serious threat to human health (1). Among all lung cancers, $\sim 80-85 \%$ are non-small cell lung cancers (NSCLC). The available treatments for patients with NSCLC are unsatisfactory; and patients demonstrate an overall 5-year survival rate of $<15 \%$ (2). With poor rates of early diagnosis and high rates of disease recurrence and metastasis, the curative effect of surgical treatment for NSCLC remains unsatisfactory. Therefore, the development of drugs for the effective treatment of NSCLC is very important.

Following years of investigation and practice, important progress has been made in the treatment of lung cancer with specific drugs (3). However, the efficacy of current existing therapeutic drugs is not satisfactory (4). In recent years, the epidermal growth factor receptor-tyrosine kinase inhibitor (EGFR-TKI) appears to offer a novel and effective therapeutic option for the treatment of lung cancer. A previous study indicated that EGFR-TKI prolongs the progression-free survival of patients with NSCLC that are sensitive to the EGFR-TKI (5). However, treatment with EGFR-TKI will inevitably result in drug resistance (6-10).

A previous study demonstrated that the B-cell lymphoma 2 (Bcl-2) expression was significantly increased in patients with NSCLC harboring EGFR mutations that were resistant to EGFR-TKI treatment (11). The anti-apoptotic gene, Bcl-2, is a key downstream effector involved in EGFR-TKI drug resistance mechanism (11). TW37 is a gossypol derivative and is an effective small molecule inhibitor of Bcl-2. It prevents Bcl-2 activation and inhibits multiple Bcl-2 family members. Recent studies indicate that TW37 may inhibit the growth of various cancer cells by inducing S-phase cell cycle arrest via regulating the expression of several important cell cycle-associated genes $(12,13)$.

In a pre-experiment performed by the authors of the present study (data unpublished), TW37 was demonstrated to induce apoptosis of the NSCLC cell line, H1975/EGFR-TKI, 
which has developed secondary resistance to EGFR-TKI. The present study was designed to investigate the effect of TW37 on H1975/EGFR-TKI cell growth and explore the underlying mechanisms.

\section{Materials and methods}

Reagents. RPMI-1640 medium, fetal bovine serum (FBS), penicillin, streptomycin and polyvinylidene fluoride (PVDF) membranes were purchased from Sigma Aldrich; Merck Millipore (Darmstadt, Germany). Primary antibodies against Bcl-2 (cat no. 15071), AKT serine/threonine kinase 1 (AKT) (cat no. 4685), phosphorylated (p)-AKT (cat no. 4060) and GAPDH (cat no. 5174), together with the corresponding secondary antibodies, anti-rabbit $\mathrm{IgG}$, horse radish peroxidase (HRP)-linked antibody (cat no. 7074) and anti-mouse IgG HRP-linked antibody (cat no. 7076), were purchased from Cell Signaling Technology, Inc. (Danvers, MA, USA). The MTT reagent and enhanced chemiluminescence (ECL) Plus reagent were purchased from Gibco; Thermo Fisher Scientific, Inc. (Waltham, MA, USA). A PIP3 Mass ELISA kit (cat no. K-2500) was purchased from Echelon Biosciences (Salt Lake City, UT, USA). The Annexin V-fluorescein isothiocyanate (FITC) apoptosis detection kit was purchased from Vazyme (Piscataway, NJ, USA). The TW37 and hematoxylin stain were obtained from Selleck Chemicals (Shanghai, China). The Transwell chamber was purchased from Jinan PengBo Biotechnology Co., Ltd. (Jinan, China).

Cell culture. The H1975/EGFR-TKI cell line, which harbors mutations in the EGFR gene at exons 21 (L858R) and 20 (T790M), was obtained from the American Type Culture Collection (Manassas, VA, USA), and cultured in RPMI-1640 supplemented with $10 \% \mathrm{FBS}, 100 \mathrm{U} / \mathrm{ml}$ penicillin and $100 \mu \mathrm{g} / \mathrm{ml}$ streptomycin. Cells were incubated at $37^{\circ} \mathrm{C}$ in a humidified atmosphere of $5 \% \mathrm{CO}_{2}$, and were passaged when they reached $90 \%$ confluence.

Cell proliferation assay. An MTT assay was performed to determine the proliferation of H1975/EGFR-TKI cells. H1975/EGFR-TKI cells growing in log-phase were trypsinized using $0.25 \%$ trypsin, and seeded in 96-well plates at a density of $5 \times 10^{3}$ cells/well. Cells were then treated with 250 , 500 and $750 \mathrm{nmol} / \mathrm{l} \mathrm{TW} 37$ for $24 \mathrm{~h}$. MTT reagent was subsequently added to the culture medium at a final concentration of $0.5 \mathrm{mg} / \mathrm{ml}$, and cells were incubated for additional $4 \mathrm{~h}$. Dimethyl sulfoxide (Sigma-Aldrich) was added to dissolve the formazan product. After incubating for $10 \mathrm{~min}$ at $37^{\circ} \mathrm{C}$, the optical density at $490 \mathrm{~nm}$ was measured using a spectrophotometer. Experiments were repeated in triplicate and the results are presented as the mean \pm standard deviation.

Apoptosis analysis. Flow cytometry analysis was performed to determine alterations in the level of apoptosis following treatment of H1975/EGFR-TKI cells with TW37.H1975/EGFR-TKI cells were treated with 250,500 and $750 \mathrm{nmol} / 1 \mathrm{TW} 37$ for $24 \mathrm{~h}$. Cells were then washed with cold phosphate-buffered saline (PBS) and fixed in $70 \%$ ethanol at $4^{\circ} \mathrm{C}$ for $30 \mathrm{~min}$, prior to exposing the cells to $20 \mu \mathrm{g} / \mathrm{ml} \mathrm{RNase} \mathrm{I} \mathrm{and} 50 \mu \mathrm{g} / \mathrm{ml}$ PI for $30 \mathrm{~min}$ at $37^{\circ} \mathrm{C}$, before they were labeled with Annexin V-FITC, according to the manufacturer's instructions (Vazyme). The level of apoptosis was assessed using a flow cytometer (BD Biosciences, Franklin Lakes, NJ, USA) was applied for cell analysis. Experiments were repeated three times.

Migration assay. To measure cell migration ability, an in vitro scratch assay was performed. H1975/EGFR-TKI cells were seeded in 6-well plates at a density of $5 \times 10^{5}$ cells/well. Cells were treated with $0,250,500$ and $750 \mathrm{nmol} / 1 \mathrm{TW} 37$ and incubated in a humidified atmosphere at $37^{\circ} \mathrm{C}$ with $5 \% \mathrm{CO}_{2}$ for $\sim 24 \mathrm{~h}$, until the cells were $80 \%$ confluent. A scratch-wound was generated using a $10-\mu 1$ pipette tip, and cells were washed three times with PBS before they were incubated in RPMI 1640 medium for $24 \mathrm{~h}$. Images were captured under an inverted light microscope (Olympus Corporation, Tokyo, Japan). The migration distance of cells was measured using ImageJ software (version 1.47; National Institutes of Health, Bethesda, USA). Experiments were repeated at least in triplicate.

Transwell invasion assay. A transwell assay was performed to measure the invasion ability of H1975/EGFR-TKI cells treated with TW37. Cells were seeded into the upper transwell chamber together with a Matrigel-coated membrane matrix, and were treated with 0, 250, 500 and $750 \mathrm{nmol} / 1$ TW37. RPMI-1640 medium containing $10 \%$ FBS was added to the lower chamber as a chemoattractant. The cells were incubated for $24 \mathrm{~h}$. At the end of the experiment, the non-invading cells on the upper surface were removed, and the cells on the lower surface were fixed with $95 \%$ ethanol for $20 \mathrm{~min}$ and stained with $0.1 \%$ hematoxylin for $30 \mathrm{~min}$, at room temperature. Stained cells were observed under an inverted light microscope (Olympus Corporation, Tokyo, Japan). A total of three independent experiments were performed.

Reverse transcription-quantitative polymerase chain reaction $(R T-q P C R)$. The mRNA expression levels of $\mathrm{Bcl}-2$ and the GAPDH housekeeping gene in H1975/EGFR-TKI cells were measured by RT-qPCR analysis. Total RNA was extracted from the cells using TRIzol reagent (Takara Biotechnology Co., Ltd., Dalian, China) according to the manufacturer's instructions. A total of $1 \mu \mathrm{g}$ RNA was then reverse transcribed into cDNA using a Revert Aid RT Reverse Transcription kit (Invitrogen; Thermo Fisher Scientific, Inc.) according to manufacturer's instructions. cDNA was subsequently amplified by qPCR using the following thermal cycling parameters: Initial activation at $95^{\circ} \mathrm{C}$ for $10 \mathrm{~min}$, followed by 40 cycles of denaturation at $95^{\circ} \mathrm{C}$ for $10 \mathrm{sec}$, annealing at $60^{\circ} \mathrm{C}$ for $60 \mathrm{sec}$ and extension at $72^{\circ} \mathrm{C}$ for $15 \mathrm{sec}$. The primers for Bcl-2 and GAPDH were as follows: Bcl-2, forward, 5'-ATGTGTGTG GAGAGCGTCAA-3', and reverse, 5'-ACAGTTCCACAA AGGCATCC-3'; GAPDH, forward, 5'-CTTTGGTATCGT GGAAGGACTC-3', and reverse, 5'-GTAGAGGCAGGG ATGATGTTCT-3'. GAPDH was selected as an endogenous reference gene to calculate the relative expression levels of Bcl-2 (14). All samples were analyzed in triplicate and three independent experiments were performed.

ELISA. H1975/EGFR-TKI cells were seeded in 6-well plates at a density of $5 \times 10^{5}$ cells per well, and were treated with 0,250 , 500 and $750 \mathrm{nmol} / 1 \mathrm{TW} 37$ for $24 \mathrm{~h}$ at $37^{\circ} \mathrm{C}$. An ELISA assay 
was performed in order to determine the expression levels of PIP3 in the cell supernatant according to the manufacturer's instructions (Thermo Fisher Scientific, Inc.), finally, the samples were examined and the absorbance was measured at a wavelength of $450 \mathrm{~nm}$. A total of three independent experiments were performed.

Western blot analysis. H1975/EGFR-TKI cells were treated with 0, 250, 500 and $750 \mathrm{nmol} / 1 \mathrm{TW} 37$ for $24 \mathrm{~h}$. Following treatment, radioimmunoprecipitation assay buffer, consisting of $50 \mathrm{mM}$ Tris- $\mathrm{Cl}$ (pH 7.4), $150 \mathrm{mM} \mathrm{NaCl}, 1 \%$ Triton X-100, $0.1 \%$ SDS and $1 \%$ sodium deoxycholate, was used to extract total cellular protein. A bicinchoninic acid assay kit (Thermo Fisher Scientific, Inc.) was used to determine the protein concentration of sample extracts. The samples (30 $\mu \mathrm{g}$ per lane) were separated on a $12 \%$ SDS-PAGE gel, and transferred to a polyvinylidene difluoride membrane. The membrane was blocked with $5 \%$ non-fat dry milk in TBS buffer containing $0.1 \%$ Tween 20 for $2 \mathrm{~h}$ at room temperature. The membrane was subsequently incubated with primary antibodies against Bcl-2, AKT, p-AKT (all diluted at 1:1,000) and GAPDH (dilution, 1:2,000) at $4^{\circ} \mathrm{C}$ for $24 \mathrm{~h}$. This was followed by incubation with the secondary antibody (dilution, 1:5,000) at room temperature for $1 \mathrm{~h}$. The membranes were then incubated with ECL Plus reagent for $30 \mathrm{sec}$ at room temperature, and scanned using the BioSpectrum Imaging System (UVP, Inc., Upland, CA, USA).

Statistical analysis. Data are presented as the mean \pm standard deviation. All statistical calculations were performed using SPSS version 11.7 software (SPSS, Inc., Chicago, IL, USA). One-way analysis of variance followed by Bonferroni post hoc test and Student's t-test were used to analyze differences between groups. $\mathrm{P}<0.05$ was considered to indicate a statistically significant difference.

\section{Results}

TW37 treatment reduces $B c l-2 m R N A$ and protein expression levels. The mRNA and protein expression levels of $\mathrm{Bcl}-2$ in H1975/EGFR-TKI cells prior to and following treatment with TW37 were detected by RT-qPCR and western blot assays, respectively. The results demonstrated that treatment with increasing concentrations of TW37 for $24 \mathrm{~h}$ was associated with a significant decrease in Bcl-2 mRNA (Fig. 1A) and a marked decrease in protein (Fig. 1B) expression levels when compared with the untreated control group.

TW37 inhibited the proliferation of H1975/EGFR-TKI cells. The effect of TW37 treatment on H1975/EGFR-TKI cell proliferation was determined. Following treatment of H1975/EGFR-TKI cells with 250, 500 and 750 nmol/1 TW37 for $24 \mathrm{~h}$, cell viability was measured using an MTT assay. The results demonstrated that TW37 significantly reduced the viability of cells (Fig. 2). This indicates that TW37 may serve an important role in inhibiting the proliferation of H1975/EGFR-TKI cells in vitro.

TW37 induced apoptosis of H1975/EGFR-TKI cells. The effect of TW37 treatment on the level of apoptosis in H1975/EGFR-TKI

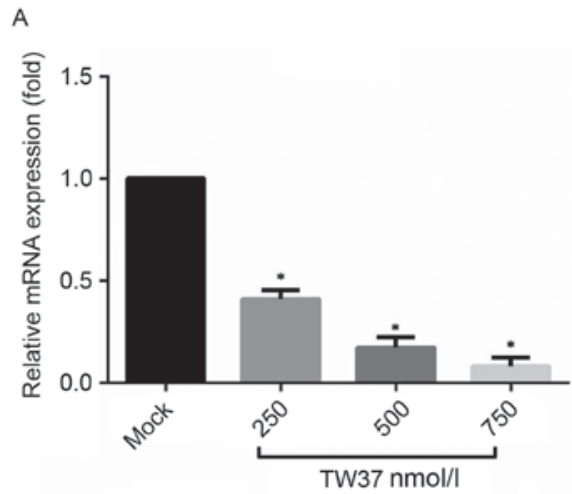

B

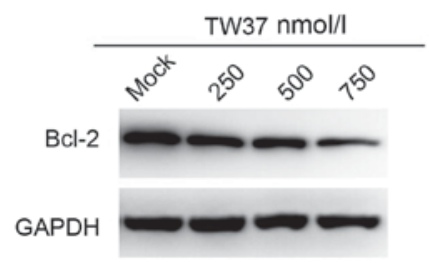

Figure 1. Expression of Bcl-2 in H1975/EGFR-TKI cells prior to and following treatment with 250,500 and $750 \mathrm{nmol} / 1 \mathrm{TW} 37$ for $24 \mathrm{~h}$. The (A) mRNA and (B) protein expression levels of Bcl-2 in H1975/EGFR-TKI cells relative to GAPDH was determined by reverse transcription-quantitative polymerase chain reaction and western blotting analyses, respectively. Experiments were performed in triplicate. ${ }^{*} \mathrm{P}<0.05$ vs. Mock. Bcl-2, B-cell lymphoma 2; EGFR-TKI, epidermal growth factor receptor-tyrosine kinase inhibitor; mock, untreated control.

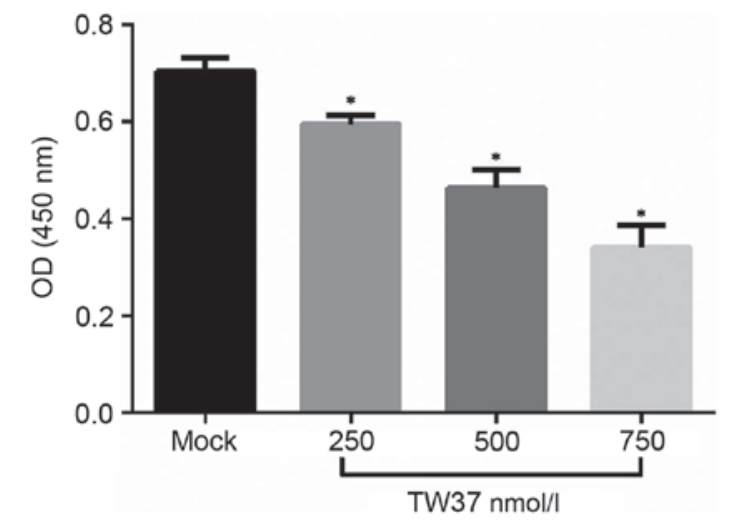

Figure 2. TW37 inhibits the proliferation of H1975/EGFR-TKI cells. The proliferation of H1975/EGFR-TKI cells following treatment with 0, 250, 500 and $750 \mathrm{nmol} / 1 \mathrm{TW} 37$ was determined using an MTT assay. The results are presented as the mean \pm standard deviation of three independent experiments. ${ }^{*} \mathrm{P}<0.05$ vs. Mock. EGFR-TKI, epidermal growth factor receptor-tyrosine kinase inhibitor; mock, untreated control.

cells was next investigated. H1975/EGFR-TKI cells were treated with 250, 500 and $750 \mathrm{nmol} / \mathrm{l} \mathrm{TW} 37$ for $24 \mathrm{~h}$, and the level of apoptosis was measured using an Annexin V-FITC apoptosis detection kit and quantified by flow cytometry analysis. As shown in Fig. 3, treatment of cells with 250, 500 and 750 nmol/1 TW37 significantly increased the level of apoptosis in a dose-dependent manner, when compared with the untreated control.

TW37 inhibited the migration and invasion abilities of H1975/EGFR-TKI cells. In order to investigate the effect of TW37 on H1975/EGFR-TKI cell migration, a scratch wound 

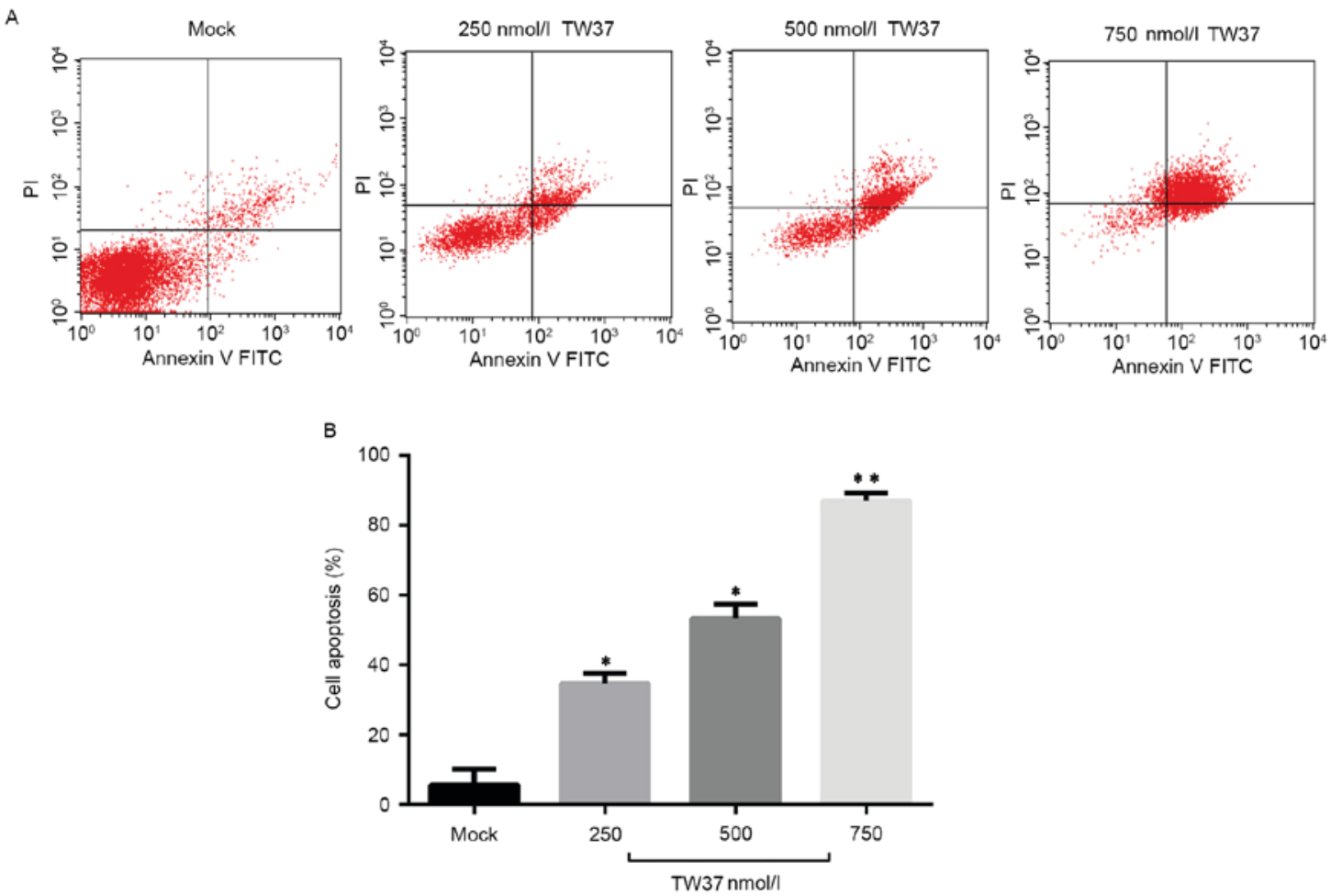

Figure 3. TW37 induces apoptosis of H1975/EGFR-TKI cells. (A) Flow cytometry analysis was performed to determine the level of apoptosis in H1975/EGFR-TKI cells treated with $0,250,500$ and $750 \mathrm{nmol} / 1 \mathrm{TW} 37$ for $24 \mathrm{~h}$, and (B) the results were quantified. Cells that stained positive for FITC-Annexin V and negative for PI were scored as exhibiting early apoptosis. Experiments were performed in triplicate. ${ }^{*} \mathrm{P}<0.05,{ }^{* *} \mathrm{P}<0.01$ vs. Mock. EGFR-TKI, epidermal growth factor receptor-tyrosine kinase inhibitor; FITC, fluorescein isothiocyanate; PI, propidium iodide; mock, untreated control.

A

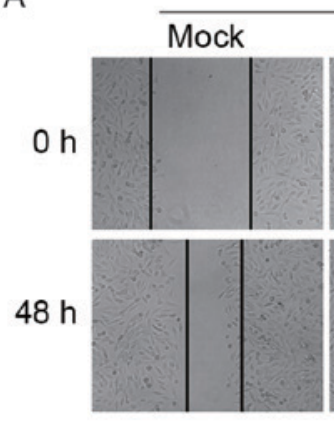

C

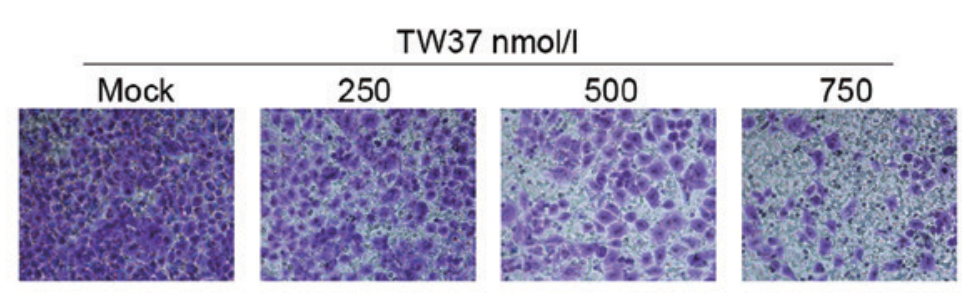

B

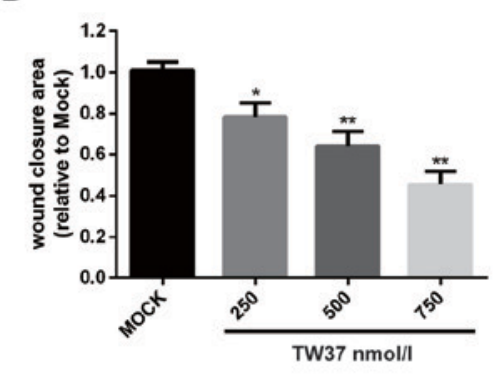

D

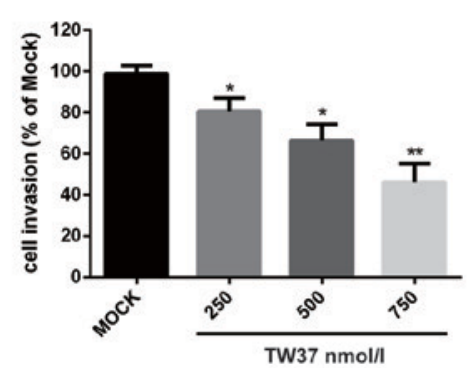

Figure 4. TW37 inhibits the migration and invasion of H1975/EGFR-TKI cells. The migration and invasion ability of H1975/EGFR-TKI cells following treatment with 0,250, 500 and $750 \mathrm{nmol} / \mathrm{l} \mathrm{TW} 37$ for $24 \mathrm{~h}$ was determined using (A and B) a cell migration and (C and D) transwell invasion assay, respectively. Experiments were performed in triplicate. Scale bars $=100 \mu \mathrm{m} .{ }^{*} \mathrm{P}<0.05,{ }^{* *} \mathrm{P}<0.01 \mathrm{vs}$. Mock. EGFR-TKI, epidermal growth factor receptor-tyrosine kinase inhibitor; mock, untreated control.

assay was performed. The results demonstrated that treatment of H1975/EGFR-TKI cells with 250, 500 and $750 \mathrm{nmol} / \mathrm{l} \mathrm{TW} 37$ reduced cell migration ability in a dose-dependent manner (Fig. 4). A transwell assay was performed to determine the effect of TW37 on cell invasion ability. Treatment of cells with 250,500 and $750 \mathrm{nmol} / \mathrm{l} \mathrm{TW} 37$ for $24 \mathrm{~h}$ significantly reduced the number of H1975/EGFR-TKI cells that migrated through the membrane in a dose-dependent manner, when compared with the control 


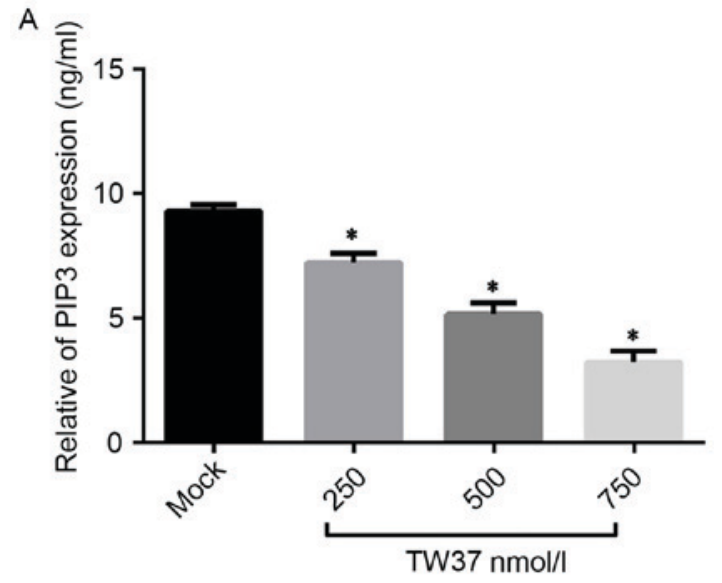

B

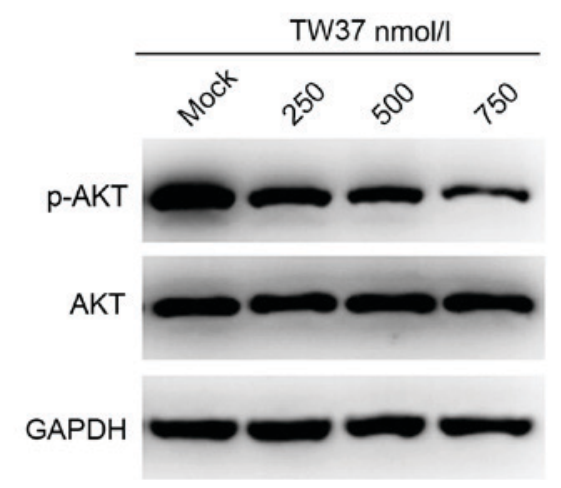

Figure 5. Expression levels of AKT, p-AKT and PIP3 in H1975/EGFR-TKI cells. H1975/EGFR-TKI cells were treated with $0,250,500$ and $750 \mathrm{nmol} / 1$ TW37 for $24 \mathrm{~h}$, and the levels of (A) PIP3 in the cell supernatant, and (B) intracellular AKT and p-AKT were measured by enzyme-linked immunosorbent assay and western blot analysis, respectively. Experiments were performed in triplicate. ${ }^{*} \mathrm{P}<0.05$ vs. Mock. AKT, AKT serine/threonine kinase 1; p-AKT, phosphorylated AKT; PIP3, plasma membrane intrinsic protein 3; EGFR-TKI, epidermal growth factor receptor-tyrosine kinase inhibitor; mock, untreated control.

group (Fig. 4). These results suggested that TW37 may inhibit the migration and invasion of H1975/EGFR-TKI cells in vitro.

TW37 inhibited the AKT signaling pathway in H1975/EGFR-TKI cells. In order to determine whether the AKT signaling pathway may be involved in mediating the effects of TW37 on H1975/EGFR-TKI cell growth, the effect of TW37 on the expression of PIP3 and the phosphorylation of AKT was determined by ELISA and western blot analyses, respectively. Following treatment of cells with 250, 500 and $750 \mathrm{nmol} / 1$ TW37 for $24 \mathrm{~h}$, the expression levels of PIP3 in the culture supernatant were detected, and the intracellular expression levels of p-AKT and AKT proteins were measured. As shown in Fig. 5, TW37 significantly reduced the production of PIP3, and markedly reduced the protein expression levels of p-AKT in a dose-dependent manner when compared with untreated controls. These results indicated that TW37 may inhibit AKT signaling pathway activation in H1975/EGFR-TKI cells.

\section{Discussion}

As a proto-oncogene, Bcl-2 inhibits apoptosis and serves important roles in the occurrence and development of tumors, as well as the development of drug resistance during the treatment of cancer (15). A recent study demonstrated that high protein expression levels of Bcl-2 are closely associated with resistance of tumor cells to chemotherapy and radiotherapy (16). Qiao et al (17) suggested that lung cancer cells exhibited an enhancement of bcl-2 mediated anti-apoptosis after treatment with chemotherapeutic drugs, thus resulting in drug resistance. Since 2009, several studies have observed high levels of Bcl-2 protein expression in a human lung cancer cell line, which developed secondary resistance to gefitinib treatment $(18,19)$. This indicated that high expression levels of Bcl-2 may be associated with the development of secondary drug resistance to EGFR-TKI. Bcl-2 is a key downstream factor of EGFR, RAS and additional signaling pathways (20). As a target for the treatment and reversal of drug resistance, Bcl-2 has recently gained significant interest. A previous study suggested that synthetic peptides and adenovirus-mediated targeted therapies inhibit the abnormal expression of Bcl-2 in tumor cells, thus effectively suppressing tumor cell growth, and reversing the resistance of cancer cells to chemotherapeutic drugs (21). TW37 is known to inhibit the growth of a variety of tumor cells, including breast, pancreatic and prostate cancer cells $(12,13)$. TW37 inhibits Bcl-2 expression and induces S-phase cell cycle arrest by regulating several important cell cycle-associated genes $(12,13)$.

The aim of the present study was to investigate the effect of TW37 on H1975/EGFR-TKI cell growth and to explore the underlying mechanisms. First, the mRNA and protein expression levels of Bcl-2 in H1975/EGFR-TKI cells prior to and following treatment with TW37 was measured by RT-qPCR and western blot analyses, respectively. The results suggested that TW37 may effectively inhibit the expression of Bcl-2. The effect of TW37 on H1975/EGFR-TKI cell growth was then determined using an MTT assay. The results indicated that TW37 significantly inhibited the proliferation of H1975/EGFR-TKI cells in a dose-dependent manner. This confirmed that TW37 demonstrated an anti-proliferative effect on H1975/EGFR-TKI cells.

A number of previous studies have reported the pro-apoptotic role of TW37 in various cancers $(12,22-24)$. The results of the current study are therefore consistent with those of previous studies. The present study suggested that the rate of H1975/EGFR-TKI cell apoptosis increased in a dose-dependent manner. The balance of cell survival and apoptosis signaling pathways is critical for determining the fate of cells, and multiple genes and molecules are involved in the regulation of this balance (25). Bcl-2 family proteins serve key roles in regulating cell apoptosis (26), and the results of the present study indicated that TW37 reduced the expression levels of the anti-apoptotic protein Bcl-2, as well as induced apoptosis of H1975/EGFR-TKI cells.

A previous study indicated that TW37 inhibited the migration and invasion of pancreatic cancer cells (27). Concordant with these findings, the results of the current study suggested that TW37 inhibited the migration and invasion of H1975/EGFR-TKI cells in a dose-dependent manner.

As one of the factors of the mitogen-activated protein kinase signaling pathway, AKT serves an important role in the regulation of cell proliferation, apoptosis and migration of cancer cells $(28,29)$. The results of the present study 
indicated that TW37 significantly decreased levels of p-AKT in H1975/EGFR-TKI cells in a dose-dependent manner. This suggests that TW37 may mediate its anti-cancer effects on H1975/EGFR-TKI cells by reducing AKT phosphorylation.

In conclusion, the current study is the first to demonstrate that TW37 significantly inhibits the proliferation, migration and invasion of H1975/EGFR-TKI cells, as well as induces apoptosis. These effects were associated with the inhibition of AKT phosphorylation. The authors hypothesize that TW37 may reverse the resistance of NSCLC cells to EGFR-TKI treatment, and may therefore serve crucial roles in improving the efficacy of drug therapy in the treatment of patients with NSCLC.

\section{Acknowledgements}

The present study was supported by the Shenzhen Commission on Technology and Innovation (grant no. JCYJ20150403091443290).

\section{References}

1. Révész D, Engelhardt EG, Tamminga JJ, Schramel FMNH, Onwuteaka-Philipsen BD, van de Garde EMW, Steyerberg EW, JansmaEP,De Vet HCW and Coupé VMH: Decision support systems for incurable non-small cell lung cancer: A systematic review. BMC Med Inform Decis Mak 17: 17-144, 2017.

2. Yang L, Parkin DM, Li LD, Chen YD and Bray F: Estimation and projection of the national profile of cancer mortality in China: 1991-2010. Br J Cancer 90: 2157-2166, 2004.

3. Swami U, Shah U and Goel S: Eribulin in non-small cell lung cancer: Challenges and potential strategies. Expert Opin Investig Drugs 26: 495-508, 2017.

4. Berhoune M, Banu E, Scotte F, Prognon P, Oudard S and Bonan B: Therapeutic strategy for treatment of metastatic non-small cell lung cancer. Ann Pharmacother 42: 1640-1652, 2008.

5. Zhang L, Li J, Hu J, Li D, Wang X, Zhang R, Zhang H, Shi M and Chen H: Cigarette smoke extract induces EGFR-TKI resistance via promoting EGFR signaling pathway and ROS generation in NSCLC cell lines. Lung Cancer 109: 109-116, 2017.

6. Inoue A, Kobayashi K, Maemondo M, Sugawara S, Oizumi S, Isobe H, Gemma A, Harada M, Yoshizawa H, Kinoshita I, et al: Updated overall survival results from a randomized phase III trial comparing gefitinib with carboplatin-paclitaxel for chemo-naïve non-small cell lung cancer with sensitive EGFR gene mutations (NEJ002). Ann Oncol 24: 54-59, 2013.

7. Mitsudomi T, Morita S, Yatabe Y, Negoro S, Okamoto I, Tsurutani J, Seto T, Satouchi M, Tada H, Hirashima T, et al: Gefitinib versus cisplatin plus docetaxel in patients with non-small-cell lung cancer harbouring mutations of the epidermal growth factor receptor (WJTOG3405): An open label, randomised phase 3 trial. Lancet Oncol 11: 121-128, 2010.

8. Rosell R, Carcereny E, Gervais R, Vergnenegre A, Massuti B, Felip E, Palmero R, Garcia-Gomez R, Pallares C, Sanchez JM, et al: Erlotinib versus standard chemotherapy as first-line treatment for European patients with advanced EGFR mutation-positive non-small-cell lung cancer (EURTAC): A multicentre, open-label, randomised phase 3 trial. Lancet Oncol 13: 239-246, 2012.

9. Sequist LV, Yang JC, Yamamoto N, O'Byrne K, Hirsh V, Mok T, Geater SL, Orlov S, Tsai CM, Boyer M, et al: Phase III study of afatinib or cisplatin plus pemetrexed in patients with metastatic lung adenocarcinoma with EGFR mutations. J Clin Oncol 31: 3327-3334, 2013.

10. Pao W and Chmielecki J: Rational, biologically based treatment of EGFR-mutant non-small-cell lung cancer. Nat Rev Cancer 10: 760-774, 2010

11. Su JC, Lin KL, Chien CM, Tseng CH, Chen YL, Chang LS and Lin SR: Naphtho[1,2-b]furan-4,5-dione inactivates EGFR and PI3K/Akt signaling pathways in human lung adenocarcinoma A549 cells. Life Sci 86: 207-213, 2010.
12. Wang Z, Azmi AS, Ahmad A, Banerjee S, Wang S, Sarkar FH and Mohammad RM: TW-37, a small-molecule inhibitor of Bcl-2, inhibits cell growth and induces apoptosis in pancreatic cancer: Involvement of Notch-1 signaling pathway. Cancer Res 69: 2757-2765, 2009.

13. Ashimori N, Zeitlin BD, Zhang Z, Warner K, Turkienicz IM, Spalding AC, Teknos TN, Wang S and Nör JE: TW-37, a small-molecule inhibitor of Bcl-2, mediates S-phase cell cycle arrest and suppresses head and neck tumor angiogenesis. Mol Cancer Ther 8: 893-903, 2009.

14. Livak KJ and Schmittgen TD: Analysis of relative gene expression data using real-time quantitative PCR and the 2(-Delta Delta C(T)) method. Methods 25: 402-408, 2001.

15. Oltersdorf T, Elmore SW, Shoemaker AR, Armstrong RC, Augeri DJ, Belli BA, Bruncko M, Deckwerth TL, Dinges J, Hajduk PJ, et al: An inhibitor of Bcl-2 family proteins induces regression of solid tumours. Nature 435: 677-681, 2005.

16. Lee HW, Choi YW, Han JH, Kim JH, Jung JH, Jeong SH, Kang SY, Choi JH, Oh YT, Park KJ, et al: Expression of excision repair cross-complementation group 1 protein predicts poor outcome in advanced non-small cell lung cancer patients treated with platinum-based doublet chemotherapy. Lung Cancer 65: 377-382, 2012.

17. Qiao GB, Zeng WS, Peng LJ, et al: Overexpression of bcl-2 and sensitivity to Platinum agents in non small cell lung cancer. J Clin Oncol 24 (Suppl): 410S-411S, 2013 (In Chinese).

18. Ma J, Zhu W and Zhou Q: Expression and Significance of bag-1, bcl-2 in Non-small cell lung cancer and the correlation with Multi-drug resistance. Zhongguo Fei Ai Za Zhi 12: 1089-1094, 2009 (In Chinese).

19. Koty PP, Zhang H, Franklin WA, Yousem SA, Landreneau R and Levitt ML: In vivo expression of p53 and Bcl-2 and their role in programmed cell death in premalignant and malignant lung lesions. Lung Cancer 35: 155-163, 2012.

20. Su JC, Lin KL, Chien CM, Tseng CH, Chen YL, Chang LS and Lin SR: Naphtho[1,2-b]furan-4,5-dione inactivates EGFR and PI3K/Akt signaling pathways in human lung adenocarcinoma A549 cells. Life Sci 86: 207-213, 2010.

21. Song JH, Kandasamy K, Zemskova M, Lin YW and Kraft AS: The BH3 mimetic ABT-737 induces cancer cell senescence. Cancer Res 71: 506-515, 2011.

22. Zeitlin BD, Joo E, Dong Z, Warner K, Wang G, Nikolovska-Coleska Z, Wang S and Nör JE: Antiangiogenic effect of TW37, a small-molecule inhibitor of Bcl-2. Cancer Res 66: 8698-8706, 2006.

23. Zeitlin BD, Spalding AC, Campos MS, Ashimori N, Dong Z, Wang S, Lawrence TS and Nör JE: Metronomic small molecule inhibitor of Bcl-2 (TW-37) is antiangiogenic and potentiates the anti-tumor effect of ionizing radiation. Int J Radiat Oncol Biol Phys 78: 879-887, 2010.

24. Wang H, Zhang Z, Wei X and Dai R: Small-molecule inhibitor of $\mathrm{Bcl}-2$ (TW-37) suppresses growth and enhances cisplatin-induced apoptosis in ovarian cancer cells. J Ovarian Res 8: 3, 2015.

25. Matsuzawa A, Nishitoh H, Tobiume K, Takeda K and Ichijo H: Physiological roles of ASK1-mediated signal transduction in oxidative stress- and endoplasmic reticulum stress-induced apoptosis: Advanced findings from ASK1 knockout mice. Antioxid Redox Signal 4: 415-425, 2002.

26. Vogler M, Walter HS and Dyer MJS: Targeting anti-apoptotic BCL2 family proteins in haematological malignancies-from pathogenesis to treatment. Br J Haematol 178: 364-379, 2017.

27. Wang Z, Song W, Aboukammad M, Mohammad M, Wang G, Banerjee S, Kong D, Wang S, Sarkar FH and Mohammad RM: TW-37, a small-molecule inhibitor of Bcl-2, inhibits cell growth and invasion in pancreatic cancer. Int J Cancer 123: 958-966, 2008.

28. Zheng Q, Wang B, Gao J, Xin N, Wang W, Song X, Shao Y and Zhao C: CD155 knockdown promotes apoptosis via AKT/Bcl-2/Bax in colon cancer cells. J Cell Mol Med: 16 Aug, 2017 (Epub ahead of print).

29. Liang Z, Wang X, Xu X, Xie B, Ji A, Meng S, Li S, Zhu Y, Wu J, $\mathrm{Hu}$ Z, et al: MicroRNA-608 inhibits proliferation of bladder cancer via AKT/FOXO3a signaling pathway. Mol Cancer 16: 96, 2017. 